\title{
A Comparative Study on the Impact of Domestic Violence According to Children's Gender
}

\author{
Misook Cho1)
}

\begin{abstract}
The purpose of this study was to investigate the impact of domestic violence according to children's gender. The findings of this study are as follows. First, a t-test was conducted to compare the differences in problem behaviors between children who experienced domestic violence and those who did not. The results showed that there were very significant differences in all areas, including sociality $(\mathrm{p}=0.0002)$, academic performance $(\mathrm{p}=0.0001)$, depression and anxiety $(\mathrm{p}=0.0001)$, delinquent behavior $(\mathrm{p}=0.0001)$, and aggressive behavior $(\mathrm{p}=0.0001)$. These results prove the argument that children subject to domestic violence suffer from "the most secretive form of abuse." Moreover, they raise the need for renewed attention to the serious and negative impact on children living together. Second, the characteristics of domestic violence according to children's gender in Korea were verified, and while the results were found to be similar to those of foreign studies, there was a reason for debate. That is, there were significant differences between the children's gender with respect to internalizing problems including depression and anxiety $(\mathrm{P}=0.006)$ and sociality $(\mathrm{P}=0.01)$. However, there were no significant differences in externalizing problems such as delinquent behavior $(\mathrm{P}=0.70)$, aggressive behavior $(\mathrm{P}=0.87)$, and academic performance $(\mathrm{p}=0.09)$. Based on these results, we discussed the need for in-depth intervention to develop a systematic domestic violence prevention network strategy according to children's gender.
\end{abstract}

Keywords: Impact, Domestic, Violence, Gender, Difference, Children, Problem, Behavior, Social, Competence

\section{Introduction}

Children adapt to adulthood by responding to and coping with various types of stressful situations. When families face very difficult circumstances, boys and girls react and cope in unique gender-specific ways to adapt to adulthood[1][2]. Gender difference is not an immutable difference caused by sex. Rather, it should be recognized as the result of interactions between biological, social, cultural, and cognitive factors, and should be understood by considering all of these aspects[3]. The reason is that children can be direct victims of domestic violence in the future, as well as perpetrators, which could have a negative impact on healthy growth and

Received(August 26, 2019), Review Result(1st: September 20, 2019, 2nd: October 31, 2019), Accepted(November 15, 2019)

1) (Professor) 01795 Department of Social Welfare, Sahmyook University, Hwarangro 815, Nowon-gu, Seoul, South Korea

email: joms@syu.ac.kr 
development according to children's gender. Rutter stated that gender is an important factor and that boys are more vulnerable to physical and psychological stress than girls[3]. On the other hand, other studies found no differences in stress response between boys and girls[4].

Based on these findings on gender differences between boys and girls, Emery even argued that a unique intervention program should be applied depending on the gender of the child[5]. However, despite the importance of problematic behaviors according to the child's gender by the impact of domestic violence, there is a lack of empirical research on this subject in Korea. In foreign countries, in-depth studies are being performed on the impact of domestic violence on children and to identify relevant variables that affect them based on their gender[6][7].

Therefore, the purpose of this study is to discuss more systematic and specific domestic violence treatment intervention and prevention strategies according to the children's gender in Korea. This will be achieved by deriving the empirical research results of Korean society based on prior studies that have been performed in Western society.

\section{Theoretical Background}

\subsection{Definition of the Harmful Effect of Domestic Violence on Children}

Stagg described domestic violence as 'a case of serious and repetitive physical injuries caused by the husband's aggressive behavior'[8], and defined the behavior as a comprehensive concept according to the times and social circumstances. Domestic violence can be classified into 4 categories(conjugal violence, child abuse, parental abuse, sibling abuse) based on the perpetrator and the victim. However, in the patriarchal social and cultural environment of Korea, assault and battery on the wife is the most common type of conjugal violence and a serious social problem[8]. Therefore, we focused the scope of this study on physical attacks against wives in the study of domestic violence.

It is also very important to determine how the impact of domestic violence on children is approached[9][10]. It would be advisable to define the psychosocial problem behaviors into three dimensions based on the classification of Achenbach and Edelbrock. This is because the harmful effects of domestic violence on children are multidimensional. Meanwhile, as domestic violence is often accompanied by child abuse[11], fathers who beat their wives are also likely to hurt their children[12]. Therefore, In light of all these issues, this paper intends to define and use the term 'child' as a family-relationship term for the parent-child interaction within the family. Children who experience domestic violence in which fathers physically abuse their 
mothers "more than 1-2 times a month" in the past year experience what we defined as the "harmful effect of domestic violence on children." The three dimensions that appear either directly or indirectly in children who experience such violence are categorized as the maladjustment to externalizing problems, internalizing problems, and social competence.

\subsection{The Three Dimensions of the Harmful Effect on Gender Differences in Children Caused by Domestic Violence}

For children in the process of growing up, complementing weaknesses and building unique strengths is as important as dealing with actual clinical symptoms. Achenbach and Edelbrock have divided childhood problems into internalizing problems, externalizing problems, and social competence[13].

1) Externalizing problems (delinquent behavior, aggressive behavior): Externalizing problems are defined as externalized and under-controlled behaviors such as delinquent behavior and aggressive behavior, which involve harming or fighting others. For example, adolescent boys may have a greater risk of externalizing problems in their development[14], and those exposed to violence between parents have a higher risk of running away from home[15].

These findings are consistent with the 'lockage phenomenon' which proposes that in conflicted or abusive families, children who experience such domestic violence can see only two possible means of escape: suicide or homicide[16]. A high rate of domestic violence is found in studies of suicide and homicide in families[17]. Furthermore, homicide often occurs when suicide attempts are unsuccessful and can be seen as an effort by children to escape from domestic violence.

2) Internalizing problems (depression and anxiety): Internalizing problems are defined as withdrawal, somatic complaints, thought problems, and attention problems, in addition to passive, socially internalized, and overcontrolled behavior. According to Caetano, Raul., Field, Craig A., \& Nelson, Scott, about 52\% of battered women suffer from severe depressive symptoms in the Beck Depression Inventory (BDI), and the BDI scores are reported to increase as the level of violence increases[9].

Depression and anxiety were prominent in children who experienced domestic violence, and boys in their early adolescence were reported to have suicidal thoughts[15]. Meanwhile, Ge et al. presented a process model which includes the influence of parameters and a direct channel through which parental life events affect children's problem behaviors. The developmental path of 'stressful life events of parents $\rightarrow$ parental depression $\rightarrow$ parenting attitude $\rightarrow$ child 
depression' was presented and verified. As a result, the life events experienced by the parents are first associated with parental depression, which interferes with the parenting attitude and increases the risk of depressive symptoms in children[18].

3) Social competence: Social competence is defined as sociality that examines the degree of socializing with friends or peers and the relationship with parents, school performance that examines if there are problems with schoolwork or academic performance, and social activities that examine the activities in peer groups. In addition to the lack of prior studies on the impact of domestic violence on children's gender, there is a lack of prior studies on sociality and academic performance in the West. Children with higher sociality or academic performance can be expected to show less problem behavior than those with lower levels of these abilities[19]. Children's social abilities were found to be negatively correlated with problem behaviors, and there was a difference between the personal and social abilities of clinical and normal groups[20]. The Child Behavior Checklist (CBCL) by Achenbach \& Edelbrock (1991) also provides a reference point for problem behaviors (e.g. the clinical reference point for internalizing problems is $70[13]$.

\subsection{Analysis of Prior Studies on the Impact of Domestic Violence According to Children's Gender}

Social learning theory explains gender differences and according to this theory, children learn by imitating behaviors they have observed or through the observation of rewards[20]. The change in imitated behavior is much larger when it comes to "same-sex" models which have familiar gender roles. In the case of violent fathers, they exhibit a more inappropriate behavioral model for boys. In contrast, girls have many internal problems but are reported to have fewer adaptation problems than boys[12][15].

However, these research results are not necessarily consistent. Sometimes boys adapt better than girls, and sometimes there are no gender differences. These differences are the results of differences in the biological, social, and cognitive factors of individual children. They will also depend on how each boy and girl understands, accepts, and copes with situations that occur in the adaptation process. Another study found that there were qualitative gender differences in the interaction with parents, in addition to the physical, cognitive, and social development of children. According to the results of prior studies performed in the West, boys who have experienced domestic violence in their original families generally experience higher levels of problem behavior. Research on the impact of domestic violence by children's gender is 
necessary for Korea. The direct and indirect summaries of results of prior studies may help initiate such research in Korea.

\section{Research Method}

\subsection{Survey Method}

The sample was centered around the middle schools where permanent rental apartments are located in five areas, including Seoul, Gyeonggi-do, and N-city and G-city in Gyeonggi Province. These areas are located within a $50 \mathrm{~km}$ radius of the university where the researcher is working. Although these areas are categorized as urban areas, they are suburban agricultural areas that are concentrated with home industries and small- and medium-sized factories and are densely populated with middle and lower-class populations. The locations of the sample were selected based on prior studies that show that the risk of domestic violence increases due to economic poverty and that families with lower incomes exhibit higher levels of domestic violence, physical abuse is more common than verbal abuse in poor families, and that children in poor families have a higher level of experience of domestic violence[8]. The survey was conducted in April 2019, and a total of 421 responses to questionnaires were used for the analysis, excluding unclear or missing cases. Among them, this study selected 85 cases (20.2\%) of domestic violence according to the children's gender. In the case of children of normal families, we randomly chose 97 cases among the remaining 336 cases in which subjects answered "none" to CTS. In total, 182 cases were used for the final analysis of this study.

\subsection{Measurement Tool}

1) "Domestic violence" scale : In this study, we modified, supplemented, and used the Conflict Tactics Scale (CTS) by Straus to measure the harmful effect of domestic violence according to children's gender[8].

2) Problem behavior scale caused by the impact of domestic violence : This study used the Child Behavior Checklist (CBCL)[13] by Achenbach \& Edelbrock to measure the impact of domestic violence on the participants.

\subsection{Analysis Method}

In this study, we used SAS/PC as the analysis method and examined the frequency and 
percentage to investigate the general background and characteristics of the participants. First, we conducted a t-test to examine if there were differences in the problem behavior between children who experienced domestic violence and those who did not. Second, a t-test was conducted to examine if there were differences in depression, anxiety, delinquent behavior, aggressive behavior, and social competence to investigate the harmful effects of domestic violence according to children's gender.

\section{Result Analysis}

\subsection{General Characteristics of Participants}

The general background and characteristics of the participants included in the analysis of this study are shown in [Table 1].

[Table 1] General Characteristics of Participants

\begin{tabular}{c|c|c|c}
\hline Category & Classification & Frequency (people) & Percentage (\%) \\
\hline Age & Average & 12.3 & 52.9 \\
Gender & Boys & 45 & 47.1 \\
\hline \multirow{2}{*}{ Economical } & Girls & 40 & 16.5 \\
condition & Upper class & 14 & 49.4 \\
& Middle class & 42 & 34.1 \\
\hline \multirow{3}{*}{ Father's education } & Lower class & 29 & 21.1 \\
& University graduate & 18 & 64.7 \\
& High school graduate & 55 & 28.4 \\
\hline \multirow{3}{*}{ Mother's education } & Middle school graduate & 12 & 12.9 \\
& University graduate & 11 & 75.3 \\
& High school graduate & 64 & 11.8 \\
\hline \multirow{5}{*}{ Father's religion } & Middle school graduate & 10 & 18.8 \\
& Buddhism & 16 & 21.2 \\
& Christianity & 18 & 10.6 \\
& Catholic & 9 & 7.1 \\
& Other & 6 & 42.3 \\
\hline \multirow{5}{*}{ Mother's religion } & N/A & 36 & 23.5 \\
& Buddhism & 20 & 28.2 \\
& Christianity & 24 & 12.9 \\
& Catholic & 11 & 8.2 \\
& Other & 7 & 27.2 \\
\hline
\end{tabular}

4.2 Comparison of Sub Factors between Children who Experienced Domestic Violence and Children of Normal Families 
In this study, we performed a t-test as shown in [Table 2] to examine whether there were differences in problem behaviors between children who experienced domestic violence and children of normal families.

[Table 2] Comparison of Sub Factors

\begin{tabular}{|c|c|c|c|c|c|}
\hline $\begin{array}{c}\text { Subfactor of } \\
\text { domestic } \\
\text { violence } \\
\text { impact } \\
\end{array}$ & Group & $\mathrm{N}$ & M & SD & $\mathrm{t}$-value ( $\mathrm{p}$-value) \\
\hline $\begin{array}{c}\text { Delinquent } \\
\text { behavior }\end{array}$ & $\begin{array}{l}\text { Children who experienced domestic violence } \\
\text { Children of normal families }\end{array}$ & $\begin{array}{l}85 \\
97\end{array}$ & $\begin{array}{l}5.63 \\
3.70\end{array}$ & $\begin{array}{l}2.70 \\
1.11\end{array}$ & $-11.23(0.0001)^{* * *}$ \\
\hline $\begin{array}{l}\text { Aggressive } \\
\text { behavior }\end{array}$ & $\begin{array}{c}\text { Children who experienced domestic violence } \\
\text { Children of normal families }\end{array}$ & $\begin{array}{l}85 \\
97\end{array}$ & $\begin{array}{l}13.07 \\
7.04 \\
\end{array}$ & $\begin{array}{l}5.25 \\
3.71\end{array}$ & $-12.20(0.0001)^{* * *}$ \\
\hline $\begin{array}{l}\text { Depression, } \\
\text { Anxiety }\end{array}$ & $\begin{array}{c}\text { Children who experienced domestic violence } \\
\text { Children of normal families }\end{array}$ & $\begin{array}{l}85 \\
97\end{array}$ & $\begin{array}{l}9.19 \\
4.72\end{array}$ & $\begin{array}{l}5.49 \\
3.52\end{array}$ & $-10.64(0.0001)^{* * *}$ \\
\hline Sociality & $\begin{array}{c}\text { Children who experienced domestic violence } \\
\text { Children of normal families }\end{array}$ & $\begin{array}{l}85 \\
97 \\
\end{array}$ & $\begin{array}{l}5.73 \\
6.22 \\
\end{array}$ & $\begin{array}{l}1.23 \\
0.96\end{array}$ & $3.74(0.002)^{* *}$ \\
\hline $\begin{array}{c}\text { Academic } \\
\text { performance }\end{array}$ & $\begin{array}{l}\text { Children who experienced domestic violence } \\
\text { Children of normal families }\end{array}$ & $\begin{array}{l}85 \\
97\end{array}$ & $\begin{array}{l}3.68 \\
4.35\end{array}$ & $\begin{array}{l}0.97 \\
0.52\end{array}$ & $9.63(0.0001)^{* * *}$ \\
\hline
\end{tabular}

${ }^{*} \mathrm{P}<.05 \quad{ }^{* *} \mathrm{P}<.01 \quad * * * \mathrm{P}<.001$

According to [Table 2], there were significant differences between children who experienced domestic violence and children of normal families in all of the scales including delinquent behavior $(\mathrm{P}=0.0001)$, aggressive behavior $(\mathrm{P}=0.0001)$, depression and anxiety $(\mathrm{P}=0.0001)$, sociality $(\mathrm{P}=0.002)$, and academic performance $(\mathrm{P}=0.0001)$.

\subsection{Comparison of Sub Factors by the Impact of Domestic Violence by Children's} Gender

[Table 3] Comparison of Sub Factors by the Impact of Domestic Violence by Children's Gender

\begin{tabular}{|c|c|c|c|c|c|}
\hline $\begin{array}{c}\text { Subfactor of } \\
\text { domestic } \\
\text { violence impact }\end{array}$ & Gender & $\mathrm{N}$ & M & SD & $\mathrm{t}$-value ( $\mathrm{p}$-value) \\
\hline \multirow{2}{*}{$\begin{array}{c}\text { Delinquent } \\
\text { behavior }\end{array}$} & Boys & 45 & 5.73 & 2.63 & \multirow{2}{*}{$0.37(0.70)$} \\
\hline & Girls & 40 & 5.71 & 2.79 & \\
\hline \multirow{2}{*}{$\begin{array}{c}\text { Aggressive } \\
\text { behavior }\end{array}$} & Boys & 45 & 13.15 & 5.90 & \multirow{2}{*}{$0.15(0.87)$} \\
\hline & Girls & 40 & 12.97 & 4.48 & \\
\hline \multirow{2}{*}{$\begin{array}{l}\text { Depression, } \\
\text { Anxiety }\end{array}$} & Boys & 45 & 7.69 & 4.60 & \multirow{2}{*}{$-2.77(0.006)^{* *}$} \\
\hline & Girls & 40 & 10.87 & 5.97 & \\
\hline \multirow{2}{*}{ Sociality } & Boys & 45 & 6.02 & 0.94 & \multirow{2}{*}{$2.37(0.01)^{* *}$} \\
\hline & Girls & 40 & 5.40 & 1.45 & \\
\hline \multirow{2}{*}{$\begin{array}{l}\text { Academic } \\
\text { performance }\end{array}$} & Boys & 45 & 3.80 & 0.66 & \multirow{2}{*}{$1.72(0.09)$} \\
\hline & Girls & 40 & 3.55 & 0.67 & \\
\hline
\end{tabular}

$* \mathrm{P}<.05 \quad * * \mathrm{P}<.01 \quad * * * \mathrm{P}<.001$ 


\section{A Comparative Study on the Impact of Domestic Violence According to Children's Gender}

The results of the t-test to examine the differences in the impact of domestic violence on children's gender are shown in [Table 3]. First, there were significant differences in the harmful effect of domestic violence according to children's gender in sociality $(\mathrm{P}=0.01)$ and depression and anxiety $(\mathrm{P}=0.006)$, which correspond to social competence. However, the values for both delinquent behavior $(\mathrm{P}=.70)$ and aggressive behavior $(\mathrm{P}=.87)$ were high without differences according to the gender, and there was also no significant difference in academic performance $(\mathrm{P}=.09)$.

\section{Conclusion and Suggestions}

Domestic violence is generally reported to have a much greater influence on the problem behavior of adolescent boys compared with girls. However, several studies have found that there were no differences in problem behavior between boys and girls[5][6]. Under these circumstances, this study was carried out as a precedent to establish a more systematic and specific domestic violence treatment and prevention intervention strategy according to children's gender. The findings of this study are summarized as follows.

First, a t-test was conducted to compare the differences in problem behaviors between children who experienced domestic violence and those who did not. The results showed that there were very significant differences in all areas, including depression and anxiety $(\mathrm{p}=0.0001)$, delinquent behavior $(p=0.0001)$, aggressive behavior $(p=0.0001)$, sociality $(p=0.002)$, and academic performance $(\mathrm{p}=0.0001)$. These results prove Walker's argument that children subject to domestic violence suffer from "the most secretive form of abuse." Moreover, they raise the need for renewed attention to the serious and negative impact on children living together. These results are also consistent with prior studies performed in other countries, and are meaningful because they could be newly confirmed from a comparative perspective in Korea.

Second, the characteristics of domestic violence according to children's gender in Korea were verified, and while the results were found to be similar to those of foreign studies, there was a reason for debate. That is scholars who have performed studies in other countries on the harmful effects of domestic violence according to children's gender report that boys show more externalizing problems such as delinquent and aggressive behavior and have lower social adaptation skills. In contrast, girls exhibit various internalizing problems but show fewer adaptation problems than boys[12][14]. However, the results of this study show significant differences between children's gender in the areas of internalizing problems such as depression and anxiety and sociality. However, there were no significant differences in externalizing 
problems including delinquent behavior, aggressive behavior, and academic performance, all of which showed high problem behavior. These results can be inferred as a result of disproving the aspect of delinquent behavior and aggressive behavior in Korean society regardless of gender. In addition, these results validate the reality of school violence in Korean society in which school violence among girls reached a similar level to that of boys. Therefore, as there are some differences between the theories derived from other countries and the reality in Korea, this study is considered to be significant in providing new implications for the intervention of domestic violence treatment and prevention programs according to children's gender.

Based on the findings above, we raise the need to plan and implement various domestic violence prevention and training programs according to children's gender. In particular, finding ways to establish and distribute education and training courses for professionals for domestic violence intervention by children's gender will be a very important task.

Finally, as this study is only the first step in identifying the differences between the harmful effects of domestic violence according to children's gender, more systematic research is required in the future. Such research should be performed through an interdisciplinary approach with various academic fields including sociology, psychology, family studies, women's studies, and psychiatry and it should be performed in conjunction with the development of treatment and prevention networks for various domestic violence interventions.

\section{Acknowledgement}

This paper was supported by the Sahmyook University Research Fund in 2019.

\section{References}

[1] P. K. Smith, L. Daglish, Sex differences in parent and infant behavior in the home, Child Development, (1977), Vol.48, No.4, pp.1250-1254, DOI: https://doi.org/10.2307/1128482

[2] Mary McGettigan-Savaresw, The intersection of woman battering and child abuse, University of Pennsylvania, Doctoral Dissertation, (2014)

[3] M. Rutter, Sex differences in children's response to family stress, The Child in his Family, Wiley, (1970)

[4] E. N. Jouriles, J. barling, K. D. O'Leary, Predicting child behavior problems in marital violent families, Journal of Abnormal Child Psychology, (1987), Vol.15, No.2, pp.165-173, DOI: 10.1007/BF00916346

[5] R. E. Emery, M. Tuer, Parenting and the marital relationship, Parenting: An Ecological Perspective, 
Lawrence Erlbaum Associates, (2013)

[6] M. O'Keefe, Factors Mediating the Link Between Witnessing Interparental Violence and Dating Violence, Journal of Family Violence, (1998), Vol.13, pp.39-57, DOI: https://doi.org/10.1023/A:1022860700118

[7] J. H. Kashani, W. D. Allan, The Impact of Family Violence on Children and Adolescents, Sage publication, (1998), pp.33-84.

[8] Cho Misook, A Study on Effectiveness of Group Program for Family Violence Assailant, Korean Journal of Clinical Social Work, The Korean Academy Of Clinical Social Work, (2015), Vol.13, No.1. pp.37-62.

[9] Raul Caetano, Craig A. Field, Scott Nelson, Association Between Physical Abuse, Exposure to Parental Violence, and Alcohol in Adulthood, Journal of Interpersonal Violence, (2003), Vol.18, No.3, pp.240-257, DOI: $10.1177 / 0886260502250074$

[10] A Field Study on Domestic Violence of whole nation, Ministry of Gender Equality \& Family Republic of Korea, (2019), pp.12-117.

[11] E. K. Suh, E. M. Abel, The impact of spausal violence on the children of the abuse, Journal of Independent Social Work, (1990), No.4, pp.27-34, DOI: https://doi.org/10.1300/J283v04n04_03

[12] A. Rosenbaum, K. D. O'Leary, Children : The Unintended Victims of Marital Violence, American Journal of Orthopsychiatry, (1981), Vol.51, No.4, pp.692-699, DOI: 10.1111/j.1939-0025.1981.tb01416.x

[13] T. M. Achenbach, C. Edelbrock, Manual for the Child Behavior Check List 4-18 and 1991 profile, University of Vermont, (1991)

[14] D. A. Wolfe, P. Jaffe, S. K. Wilson, L. Zak, Children of Battered Women : The Relation of Child Behavior to Family Violence and Maternal Stress, Journal of Counseling and Clinical Psychology, (1985), Vol.53, No.5, pp.657-665, DOI: 10.1037//0022-006X.53.5.657

[15] B. E. Carlson, Adolescent observers of marital Violence, Journal of Family Violence, (1990), Vol.5, No.4, pp.285-299, DOI: 10.1007/BF00979065

[16] M. A. Straus, Children as Witness to Marital Violence: A Risk Factor for Life Long Problems among a Nationally Representative Sample of American Men and Women, Paper presented at the Ross Roundtable, ED336713, (1991)

[17] J. H. Kashani, P. J. Darby, W. D. Allan, K. L. Hartke, J. C. Reid, Intrafamilial Homicide Committed by Juveniles: Examination of a Sample with Recommendations for Prevention, Journal of Forensic Sciences, (1997), Vol.42, No.5, pp.873-878, DOI: 10.1520/JFS14222J

[18] X. Ge, R. D. Conger, F. O. Lorenz, R. L. Simons, Parents' stressful life events and adolescent depressed mood, Journal of Health and Social Behavior, (1994), Vol.35, No.1, pp.28-44, DOI: 10.2307/2137333

[19] E. A. Blechman, B. Tinsley, E. T. Carella, M. J. McEnroe, Childhood competence and behavior problems, Journal of Abnormal Psychology, (1985), Vol.94, No.1, pp.70-77, DOI: 10.1037/0021-843X.94.1.70

[20] E. L. Geston, A health resources inventory: The development of a measure of the personal and social competence of primary-grade children, Journal of Consulting and Clinical Psychology, (1976), Vol.44, No.5, pp.775-786, DOI: 10.1037/0022-006X.44.5.775 